Original article

\title{
Do different groups have different risk factors for dieting and exercise as body management strategies?
}

\author{
Behshid Garrusi, Mohammad Reza Baneshi, Fatemeh Amiri \\ Kerman University of Medical Sciences, Kerman, Iran
}

Received 17 October 2012, Revised 27 Oct 2012, Accepted 31 Oct 2012.

C 2012, Garrusi B., Baneshi M.R., Amiri F.

(C) 2012, Russian Open Medical Journal

Abstract: Aim - Body change strategies are activities that could be potentially harmful. Individuals may use different methods for achieving advertised ideal body. Some of demographic and psychosocial contributing factors could be affect decision regarding body management activities. In Iran there is a few research about this matter, therefore the aim of this study was exploring risk factors in body management. Materials and Methods - In this cross sectional study, 400 people participated that including general population, university students and body building clubs attainders. The self administrated questionnaire based on reliable sources of body image that evaluated its validity and validity. Statistical analysis was done by using central indexes and distribution and logistic regression. Data analysis was done by software of SPSS 16. Results - Marital status, education, economic status, age and BMI had no relation with body management strategies. Birthplace effects on choose of diet and exercise. Gender is only had effect on exercise choosing. Use of Western TV had effect on doing exercise. Pressure of relatives was an important factor in decision about dieting. Self steam and compare of appearance with others affected choosing of dieting. There were no differences between selected groups. Conclusion - In spite of similarities between body dissatisfaction and its management strategies with other studies in Iran, there is necessity for future studies.

Keywords: dieting, exercise, body image, Iran.

Cite as Garrusi B, Baneshi MR, Amiri F. Do different groups have different risk factors for dieting and exercise as body management strategies? Russian Open Medical Journal 2012; 1: 0308.

Correspondence to Behshid Garrusi. Address: Department of Community Medicine, Afzallipour Medical School, Kerman University of Medical Sciences, Kerman, Iran(IR). Tel: +98-341-3224613. Fax: +98-341-3221671. E-mail: bgarrusi@kmu.ac.ir, behshidgarrusi@gmail.com.

\section{Introduction}

While concerns about one's body and degree of physical attractiveness have been a part of history, these concerns have become more intense in recent decades. Body image has been defined as the perception of overall physic cal appearance. It consider a multidimensional issue that includes perception, attitude, feeling and the effects of these perceptions on the individual's behaviors [1]

Body size estimation, attractiveness and one's feelings about these are among the aspects of body image [1]. Body image is the mental representation about own body. Body satisfaction and its related problems were, in the past, known as a western culture phenomenon; however, recent studies are finding that it is now a worldwide matter. Despite previous beliefs, body concerns and eating disorders are increasing in Asian countries, and in some of these societies, their prevalence is similar to that of western cultures [2, 3]. In recent decades, the emphasis for the ideal women has been on thinness, while the emphasis for the ideal man has been on muscledevelopment/masculinity [4]. These body characteristics are considered symbols of success, self control and sexual attractiveness in women and empowerment in men [1,4].

There are multiple differences between Asian cultures that can affect an individual's perceptions, attitudes and behaviors [5]. For example, in east Asia, Japanese women suffer more from eating disorders and body dissatisfaction than Taiwanese women [6]. Researchers contend that there are many cultural differences within east Asian countries [7] as well as significant differences between eastern and western Asian cultures.

Body image and body satisfaction can be affected by many socio-cultural factors $[8,9]$. Culture plays a significant role in the conceptualization of beauty and attractiveness [8]. Desire for achieving of Ideal body, could be cause some of health consequences, such as eating disorders and unhealthy behaviors for body change. Body dissatisfaction is correlated with various attempts to change one's body, and these efforts can begin in children as young as 5 -years-old $[10,11]$. The most accepted method is dieting, a method that can result inanorexia, if successful and encouraged by others,orbulimia, which hascompensatory activities such as induced vomiting and theuse of laxatives [12]. As previously stated, females wish to be thinner, and males wish to be more masculine [10]. These desires can cause males to exercise excessively and engage in steroid use,whilefemalesprefer dieting strategies or surgery. In somestudies, however,body image dissatisfaction negatively correlated with physical activity, especially among adolescent girls [10]. The aim of this identifying of body change strategies that were chosen by different groups in one Iranian sample. 


\section{Material and Methods}

This population-based study was carried out in Kerman, the capital of the largest province in Iran. The main outcomes of the study include body change strategies. We focused on two main methods: diet (restricted food, induced vomiting) and exercise (heavy exercise for masculinity or weight reduction). In this study, was done in three different group, general population, university students and body building (gym) users. These participants were selected) by multistage sampling.

\section{Self-administrated questionnaire include below parts:}

Demographic variables: Age ( $>20,<20$ years), gender (male, female), economical status (fair to medium and good to excellent), marital status (married, single), place of birth (big cities, small cities and village), BMI (cut-offs at 18.5, 24.9, and 29.9, subjects were categorised into four groups: $\mathrm{BMI}<18.5$ (thin), $\mathrm{BMI}=18.5-24.9$ (normal), $\mathrm{BMI}=25-29.9$ (overweight), $\mathrm{BMI}>30$ (obese), use of media (TV, fashion magazine).

Socio-cultural variables: This parts evaluated comparison of body with others \{Physical Appearance Comparison Scale (PACS)\}, that had acceptable reliability and validity in Persian [13], perceived pressure from relatives \{Perceived Socio-cultural Pressure Scale (PSPS)\}, Body Satisfaction (Figure Rating Scale ) that subjects were classified into three groups: no body dissatisfaction their current and ideal shapes were the same), mild dissatisfaction (BD score of 1), and severe dissatisfaction (the difference was greater than 1), and Self Steam \{Rosenberg self steam scale (RES)\}. This study was approved by Ethical Committee of Kerman Medical Sciences University.

\section{Statistical analysis}

Descriptive statistics were used to summarise the data. A series of multifactorial logistic regression models were applied to identify the factors that influence each of the outcomes or body management methods (i.e., diet, exercise). The results are presented in terms of the odds ratio (OR), associated 95\%confidence intervals $(\mathrm{Cl})$, and $\mathrm{P}$-value.

In addition, the probability of outcomes was estimated from developed logistic models. The estimated probabilities were then compared with the observed individual's status to calculate the correct classification proportion. $\mathrm{P}<0.05$ was considered as significant.

\section{Results}

About $48.5 \%$ (149) of 400 respondents were female. The mean (SD) for age in three groups (general population, university students, gym users) were 27.6 (8.36), 23.13 (3.29), 22.09 (2.19) years, respectively. Some of demographic characteristics of respondents were shown in Table 1. Mean of BMI in three groups were $23.75(4.12), 49(3.5), 22.90(2.96) \mathrm{kg} / \mathrm{m}^{2}$ inprevious groups (Table 1). Frequencies of Body Dissatisfaction categories in participants were listed in Table 2.

Regarding the factors that encourage people to manage their body shape through dieting, we find that pressure from relatives (PSPS) (Cl 95\%: 0.83-0.95, $\mathrm{P}=0.01$, own comparison with others (PACS) (CI 95\%: 1.01-1.16, $P=0.029$ ), self steam (Cl 95\%: 1.01-1.38, $\mathrm{P}=0.029$ ) where are all influencing variables (Table 3 ). Belonging to specific group, and gender, there were no effect for decision regarding choose of body image strategies.
With respect to exercise, we find that gender $(\mathrm{Cl} 95 \%$ : 0.19$0.68, \mathrm{P}<0.001)$ and use of western TV (Cl 95\%: 1.16-3.92, $\mathrm{P}=0.014)$, were important factors. It shows that other factors such as scores of PACS, and PSPS or other socio-cultural variables, there were not influencing factors. Choosing of body management strategies had not affect by belonging to special groups.

Place of birth had significant effect on dieting (Cl 95\%: 1.3513.01, $P=0.013$ ) and exercise ( $\mathrm{Cl} 95 \%$ : 0.12-0.80, $\mathrm{P}=0.016)$. Participants who were born in big cities were 4.1 times more likely to manage their body shape through dieting. Born in big cities was increased chance of using exercise as a body change strategies about 30\% (Table 4).

Table 1. Demographic characteristics of respondents

\begin{tabular}{|l|c|c|c|}
\hline \multirow{2}{*}{ Variable } & Level & Frequency & Percent \\
\hline \multirow{2}{*}{ Gender } & $<20$ & 85 & 21.2 \\
\cline { 2 - 4 } & $>20$ & 315 & 78.8 \\
\hline \multirow{2}{*}{ Marital status } & Female & 194 & 48.5 \\
\cline { 2 - 4 } & Male & 206 & 51.5 \\
\cline { 2 - 4 } & Single & 279 & 69.8 \\
\hline \multirow{2}{*}{ Education } & Married & 121 & 30.2 \\
\cline { 2 - 4 } & University degree & 73 & 18.2 \\
\hline \multirow{2}{*}{ Economic Status } & Fair-medium & 327 & 81.8 \\
\cline { 2 - 4 } & Good-excellent & 154 & 61.5 \\
\hline
\end{tabular}

Table 2. Distribution of body dissatisfaction

\begin{tabular}{|l|l|c|c|c|}
\hline & & $\begin{array}{c}\text { General } \\
\text { population }\end{array}$ & $\begin{array}{c}\text { University } \\
\text { Students }\end{array}$ & $\begin{array}{c}\text { Gym } \\
\text { users }\end{array}$ \\
\hline \multirow{2}{*}{$\begin{array}{l}\text { Body } \\
\text { Dissatisfaction (BD) }\end{array}$} & Mild BD & $14.3 \%$ & $17.8 \%$ & $8.0 \%$ \\
\cline { 2 - 5 } & Severe BD & $6.8 \%$ & $9.5 \%$ & $3.5 \%$ \\
\hline
\end{tabular}

$\mathrm{BD}=$ Body Dissatisfaction

Table 3. Identification of factors that encourage people to diet as a way to manage their body shape through a multi factorial logistic regression

\begin{tabular}{|l|c|c|c|}
\hline \multicolumn{1}{|c|}{ Variable } & OR & Cl 95\% & P-level \\
\hline Age & 0.50 & $0.39-1.47$ & 0.407 \\
\hline Gender & 1.03 & $0.59-1.79$ & 0.931 \\
\hline Education & 0.93 & $0.46-1.90$ & 0.85 \\
\hline Marital status & 0.61 & $0.33-1.10$ & 0.102 \\
\hline Place of Birth & 4.19 & $1.35-13.01$ & 0.013 \\
\hline Economic Status & 1.74 & $1.0-3.04$ & 0.05 \\
\hline Western TV & 0.66 & $0.39-1.11$ & 0.118 \\
\hline $\begin{array}{l}\text { Study Group: } \\
\text { - Body building (gym )users }\end{array}$ & 1.66 & $0.77-3.61$ & 0.197 \\
- University students & 1.16 & $0.61-2.19$ & 0.652 \\
\hline $\begin{array}{l}\text { PSPS (Perceived Socio-Cultural } \\
\text { Pressure Scale) }\end{array}$ & 0.89 & $0.83-0.95$ & 0.01 \\
\hline $\begin{array}{l}\text { PACS (Physical Appearance } \\
\text { Comparison Scale) }\end{array}$ & 1.08 & $1.01-1.16$ & 0.029 \\
\hline BMI (Body Mass Index) & 0.97 & $0.91-1.05$ & 0.474 \\
\hline $\begin{array}{l}\text { Body Dissatisfaction (BD): } \\
\text { - Mild BD }\end{array}$ & 1.38 & $1.01-1.38$ & 0.029 \\
\hline - Severe BD & 0.60 & $0.34-1.06$ & $\begin{array}{l}0.081 \\
0.53-2.50\end{array}$ \\
\hline RES (Rosenberg Self Steam) & & & 0.727 \\
\hline
\end{tabular}


Table 4. Identification of factors that encourage people to exercise as a way to manage their body shape through a multi factorial logistic regression

\begin{tabular}{|l|c|c|c|}
\hline \multicolumn{1}{|c|}{ Variable } & $O R$ & Cl 95\% & P-level \\
\hline Age & 0.95 & $0.48-1.90$ & 0.888 \\
\hline Gender & 0.36 & $0.19-0.68$ & 0.001 \\
\hline Education & 0.54 & $0.23-1.26$ & 0.155 \\
\hline Marital status & 2.09 & $1.01-4.32$ & 0.48 \\
\hline Place of Birth & 0.30 & $0.12-0.80$ & 0.016 \\
\hline Economic Status & 1.01 & $0.55-1.40$ & 0.979 \\
\hline Western TV & 2.13 & $1.16-3.92$ & 0.014 \\
\hline $\begin{array}{l}\text { Study Group: } \\
\text { - Body building (gym )users } \\
\text { - University students }\end{array}$ & 1.30 & $0.53-3.19$ & 0.563 \\
\hline $\begin{array}{l}\text { PSPS (Perceived Socio-Cultural Pressure } \\
\text { Scale) }\end{array}$ & 1.49 & $0.74-2.99$ & 0.261 \\
\hline $\begin{array}{l}\text { PACS (Physical Appearance Comparison } \\
\text { Scale) }\end{array}$ & 1.04 & $0.96-1.12$ & 0.34 \\
\hline BMI (Body Mass Index) & $0.93-1.08$ & 0.953 \\
\hline $\begin{array}{l}\text { Body Dissatisfaction (BD): } \\
\text { - Mild BD }\end{array}$ & 0.97 & $0.90-1.05$ & 0.479 \\
\hline - Severe BD & & & \\
\hline RES (Rosenberg Self Steam) & 0.78 & $0.41-1.46$ & 0.436 \\
& 0.81 & $0.36-1.84$ & 0.62 \\
\hline
\end{tabular}

\section{Discussion}

Among contributing factors that could be affect decision about body change activities, body dissatisfaction is considered as an important factors. Body dissatisfaction is known significant predictors of body change activities for women [14]. The desire for thinness as an appearance-related reason for exercise is associated with body dissatisfaction and low self-esteem. In some studies, however, body image dissatisfaction negatively correlated with physical activity, especially among adolescent girls [15]. Some studies found that body satisfaction in women has a greater effect on self-esteem than in men. Chronic dieters have increased body dissatisfaction and lower self-esteem [16]. It was surprising that in recent study, body dissatisfaction had no effect on body management strategies. Body image and body satisfaction can be affected by many socio-cultural factors [8], that may be a greater role in body change activities. Although this effect on dieting was evident in both genders, dieting was more prominent in males [17]. However, according previous studies, we found that selfesteem had contributing effect on body change activities especially in dieting.

Socio-cultural variables are important factors that contribute to body dissatisfaction and related problems such as desire for body management strategies. One of the socio-cultural factors that may affect an individual's desire to be thin or masculine and a person's decision regarding body change strategies is perceived pressure from family, friends and/or the media [8]. One of the social groups for comparison is the peer group. Peer groups have a significant effect on body satisfaction and body change activities. The effect of peers with ideal body types was associated with longer periods of exercise, especially for women. Although this comparison appears higher in females, peer effect on body satisfaction and decisions about body changes are found in both genders [4]. In our study, dieting was influenced by comparison with others and family and peer pressures.
Body image is affected by environment and cultural issues. In big cities, individuals are more prone to media or social pressure such as fashion, magazines, beauty contest. In addition, in big cities, social situations and marriage could be related to attractive appearance [18]. Ideal body image is promoted through the media that suggests thinness is the sign of attractiveness. Despite the desire to increase muscle mass, weight concerns and dieting are also important for males [19]. Although heavy exercise was done for weight loss achievement of masculinity especially for male adolescents. Effects of born in big cities and western TV. On body management strategies were shown in recent study. Such as previous researches, gender could be an important factor for decision about body management. Belonging to specific group, there was no effect on body management activity. The reason of this finding may be due to greater power of other contributing factors such as pressure from relatives, friends and media. Based on this studies 'results, body management strategies in different cultures were different.

\section{Conclusion}

Body image and related consequences such as body change activities are new issues in Iran. It seem socio-cultural factors are important predictive factors for body change activities. White considering differences between Asian culture, in planning for harm reduction of unhealthy behavior in dieting or exercise, culture must be consider seriously. Future Asian transcultural studies about these differences are advised.

Acknowledgement: This research was financially supported by Neurosciences Research Center of Kerman University of Medical Sciences.

Conflict of interest: none declared.

\section{Reference}

1. Tiggemann M. Body image across the adult life span: Stability and change. Body Image 2004; 1: 29-41 (PMID: 18089139).

2. Xu X, Mellor D, Kiehne M, Ricciardelli LA, McCabe MP, XuY. Body dissatisfaction, engagement in body change behaviors and sociocultural influences on body image among Chinese adolescents. Body Image 2010; 7(2): 156-164 (PMID: 20089467).

3. Lee $A M$, Lee $S$. Disordered eating in three communities of China: A comparative study of female high school students in Hong Kong, Shenzhen and rural Hunan. Int J Eat Disord 2000; 27: 317-327 (PMID: 10694718)

4. Ricciardelli LA, McCabe MP. A biopsychosocial model of disordered eating and the pursuit of muscularity in adolescent boys. Psychol Bull 2004; 130: 179-205 (PMID: 14979769).

5. Yates A, Edman J, Aruguete M. Ethnic differences in BMI and body/self-dissatisfaction among Whites, Asian subgroups, Pacific Islanders, and African-Americans. Jour Adolesc Health 2004; 34(4): 300-307 (PMID: 15040999).

6. Shih $M$, Kubo $C$. Body shape preference and body satisfaction in Taiwanese college students. Psychia Resear 2002; 111: 215-228 (doi: 10.1016/S0165-1781(02)00138-5).

7. Ryu HR, Lyle RM, McCabe GP. Factors associated with weight concerns and unhealthy eating patterns among young Korean females. Eat Disord 2003; 11: 129-141 (PMID: 16864515).

8. Jackson $\mathrm{T}$, Chen $\mathrm{H}$. Sociocultural predictors of physical appearance concerns among adolescent girls and young women from China. Sex Roles 2008; 58: $402-411$ (doi: 10.1007/s11199-007-9342-x).

9. Stice E. Review of the evidence for a socio-cultural model of bulimia nervosa and exploration of the mechanisms of action. Clin Psychol Rev 1994; 14: 633-661 (doi: 10.1016/0272-7358(94)90002-7). 
10. McCabe MP, Ricciardelli LA. Sociocultural influences on body image and body changes among adolescent boys and girls. I Soc Psychol 2003; 143(1): 5-26 (PMID: 12617344).

11. Davison KK, Markey CN, Birch LL. Etiology of body dissatisfaction and weight concerns among 5-year-old girls. Appetite 2000; 35: 143-151 (PMID: 10986107).

12. Stice E, Hayward C, Cameron R, Killen JD, Taylor CB. Body image and eating related factors predict onset of depression in female adolescents: a longitudinal study. J Abnorm Psychology 2000; 109: 438-444 (PMID: 11016113).

13. Garrusi B, Garousi S ,Baneshi MR. Body image and body change: predictive factors in an Iranian. IJPM 2012 [In press].

14. Cachelin FM, Veisel C, Barzegarnazari E, Streigel-Moore RH. Disordered eating, acculturation, and treatment seeking in a community sample of Hispanic, Asian, Black, and White women. Psychol Women Q 2000; 24: 244-253 (doi: 10.1111/j.1471-6402.2000.tb00206.x).

15. Neumark-Sztainer D, Wal M, Eisenberg ME, Story M. Obesity and eating disorders in older adolescents: Does early dieting make things better or worse? J Adolesc Health 2005; 36: 152-153 (doi: 10.1016/j.jada.2006.01.003).

16. Gingras J, Fitzpatric J, Mccargar L. Body Image of Chronic Dieters: Lowered Appearance Evaluation and Body Satisfaction. J Am Diet Assoc 2004; 104: 1589-1592 (doi: 10.1016/j.jada.2004.07.025).

17. Friestad C, Rise J. A longitudinal study of the relationship between body image, self esteem and dieting among 15-21 year olds in Norway. Eur Eat Disord Rev 2004; 12: 247-255 (doi: 10.1002/erv.570).

18. Hasmukh SH, WasimSH, Singh S. Are Indian Adolescents girl students more conscious about their body image than their colleague boys? National Journal of Community Medicine 2012; 3(2): 344-347.

19. Hargreaves D, Tiggemann M. The effect of 'thin ideal' television commercials on body dissatisfaction and schema activation during early adolescence. J Youth Adolesc 2003; 32: 367-373 (doi: 10.1023/A:1024974015581).

Authors:

Behshid Garrusi - MD, Associate Professor of Psychiatry, Neuroscience research center, Department of community medicine, Afzallipour Medical School, Kerman University of Medical Sciences, Kerman, Iran;

Mohammad Reza Baneshi - PhD, Assistant Professor of Statistics, Research Center For Modeling in Health, Kerman University of Medical Sciences, Kerman, Iran;

Fatemeh Amiri - MD, Student Research Center, Kerman University of Medical Sciences, Kerman, Iran 